\title{
Magia, Experiências Extáticas e a dimensão popular do Protocristianismo
}

\author{
Magic, Ecstatic Experiences and the popular dimension \\ of Early Christianity
}

\section{Magia, experiencias extáticas y la dimensión popular del protocristianismo}

\author{
Prof. Dr. Marcelo da Silva Carneiro* \\ Submetido em: 22-3-2021 \\ Aceito em: 05-05-2021
}

\author{
* Universidade Metodista de São Paulo \\ Docente do Programa de Pós-Graduação \\ em Ciências da Religião da Universidade \\ Metodista de São Paulo \\ professor.carneiro@hotmail.com
}

\begin{abstract}
RESUMO
Esse artigo, com características de ensaio acadêmico, tem como objetivo apresentar um panorama de pesquisas a respeito das experiências religiosas do protocristianismo, a partir de sua dimensão popular. Dentre as diferentes expressões dessas experiências, serão apresentados aspectos importantes para esse panorama, como a magia e as experiências extáticas, destacando-se aqui as viagens celestiais e a glossolalia, além do exorcismo. Busca-se indicar um caminho de superação do racionalismo acadêmico, que tende a considerar esses elementos secundários e até irrelevantes para o estudo do Novo Testamento e outros textos extracanônicos.

Palavras-chave: Magia; protocristianismo; cultura popular; experiências extáticas; glossolalia.
\end{abstract}

\begin{abstract}
This article, with academic essay characteristics, aims to present an overview of research about the religious experiences of proto-Christianity, from its popular dimension. Among the different expressions of these experiences, important aspects will be presented for this panorama, such as magic and ecstatic experiences, highlighting here the heavenly journeys and glossolalia, in addition to exorcism. It seeks to indicate a path of overcoming academic rationalism, which tends to consider these elements as secondary and even irrelevant to the study of the New Testament and other extracanonical texts.

Keywords: Magic; Early Christianity; popular culture; ecstatic experiences; glossolalia.

\section{RESUMEN}

Este artículo, con características de ensayo académico, tiene como objetivo presentar una visión general de la investigación sobre las experiencias religiosas del protocristianismo, desde su dimensión popular. Entre las diferentes expresiones de estas experiencias, se presentarán aspectos importantes para este panorama, como la magia y las experiencias extáticas, destacando aquí los viajes celestes y la glosolalia, además del exorcismo. Busca indicar un camino de superación del racionalismo académico, que tiende a considerar estos elementos secundarios e incluso irrelevantes para el estudio del Nuevo Testamento y otros textos extracanonicos. Palabras clave: Magia; protocristianismo; cultura popular; experiencias extáticas; glosolalia.
\end{abstract}




\section{Superando as leituras convencionais}

Uma memória que tenho de meus tempos de seminário era a dificuldade de manter o povo da comunidade vivenciando sua experiência de fé apenas dentro dos parâmetros eclesiásticos definidos. Parte da comunidade, movida pelo desejo de saber o que "Deus tinha para dizer sobre sua vida", começou a procurar uma profetisa que vivia em certo bairro próximo e recebia as pessoas em casa. Lá, ela orava e recebia recados divinos para as pessoas, orava pela cura e dava orientações sobre práticas necessárias para fortalecer a vida espiritual. Em geral, eram jejuns específicos, leituras da Bíblia e determinado procedimento para oração.

Essa prática, pensada em termos do fenômeno religioso em geral, pode ser percebida também no protocristianismo. ${ }^{1}$ Ocorre que a maioria dos trabalhos sobre o Novo Testamento tem como ponto de partida a preocupação com a doutrina que era desenvolvida a partir dos escritos e originou a ortodoxia, aspectos dessa doutrina estudados de forma mais aprofundada, como a cristologia, a soteriologia, dentre outros, e questões teológicas que atendessem às necessidades pastorais e eclesiásticas atuais. Ao mesmo tempo, as pesquisas críticas se debruçaram cada vez mais nos aspectos da formação do texto, sua transmissão e interpretação, além das pesquisas sobre Jesus e Paulo dentro de seu mundo social, em uma busca de localizá-los historicamente.

Pouco valor, porém, é dado a elementos menos glamorosos ou que estivessem naquilo que poderíamos chamar de "o fundamento dos apóstolos e profetas". Poderíamos denominar esses elementos como a dimensão popular do protocristianismo, ou ainda as evidências textuais que falam das múltiplas formas de experiência religiosa que tiveram as comunidades cristãs iniciais, em sua própria interpretação dos eventos e expressão de piedade. A riqueza dessas experiências, documentadas em relatos diretos e indiretos, poéticos e, ao mesmo tempo, testemunhais de fatos vividos, tem sido, mais recentemente, objeto de estudo por parte de diversos pesquisadores e pesquisadoras, tanto no Brasil quanto em outros países. O interesse pelo descortinamento da vivência de fé do protocristianismo tem se tornado alvo de cada vez mais destaque no cenário acadêmico. No ambiente das Ciências da Religião, principalmente, segundo o que o Programa de Pós-Graduação

\footnotetext{
1 Termo adotado por nós para falar das diferentes experiências cristãs anteriores ao surgimento do Cristianismo como religião plenamente institucionalizada, no século IV EC. Semelhante ao termo Cristianismo Primitivo, tem a vantagem de acolher dentro dele as múltiplas expressões, sem definir qual delas seria a correta. Poderia ser usado no plural, como fazem com o termo Cristianismos Originários, mas o uso de "proto" já define algo anterior, não estruturado.
} 
busca na Universidade Metodista de São Paulo (UMESP), esses recortes de pesquisa se tornaram essenciais para perceber de maneira mais eloquente o cenário no qual se deu o desenvolvimento das comunidades cristãs iniciais.

Neste artigo, iremos apresentar alguns desses temas, explorados em diversas pesquisas, fundamentadas em trabalhos já consagrados, tanto no cenário nacional quanto internacional. Considerando que entendemos que o protocristianismo se desenvolveu a partir de uma grande rede textual (oral e escrita) e cultural, também as pesquisas a respeito de suas diferentes vivências e experiências religiosas acabam gerando um tipo de rede textual, bastante promissora no sentido de dar uma visão ampla de conjunto. Por isso, nosso trabalho tem mais a forma de um ensaio do que de artigo propriamente dito, pois procurará indicar os caminhos da pesquisa em torno desses temas.

Inicialmente apresentaremos as pesquisas nas quais se aborda o protocristianismo como religião popular. Um recorte que supera a visão de um cristianismo homogêneo e organizado a partir de cima, em que as divergências eram combatidas e que já tinha uma fronteira bem estabelecida como grupo religioso. A partir dessa ideia maior, apresentaremos as pesquisas mais específicas, que mostram as expressões religiosas do protocristianismo, em especial a ideia de magia e as experiências extáticas, dentre as quais serão destacadas as viagens celestiais, a glossolalia, bem como o imaginário em torno do exorcismo.

\section{O protocristianismo como religião popular}

A ideia não deveria ser estranha - pensar o protocristianismo como um movimento de fé em torno de Jesus de Nazaré, considerado o Cristo. Afinal, as pessoas que aderiram à fé eram da população em geral, quase ninguém oriundo das classes mais elevadas e da nobreza. As notícias de Atos, de que sacerdotes (At 6.7) e pessoas da administração judaica (Lc 8.3) se convertiam, mesmo se consideradas históricas, são casos excepcionais e em número muito menor que o grande número de conversões indicadas entre o povo (At 2.41; 5.14; 8.6 etc.). Neste caso, não estamos falando de gente sofisticada, com alto nível de qualidade de vida ou educação, mas pessoas simples, camponesas, escravas, de baixo nível social.

Entretanto, muitos estudos e a forma como se aborda o protocristianismo em muitos manuais não negam, mas acabam ocultando essa faceta. Ou ainda, tornam-na secundária ou marginal ao estudo do movimento nos séculos I e II EC. Um bom exemplo é a forma como S. Vernon McCasland (1951) expõe o mundo greco-romano num dos artigos introdutórios ao Novo Testamento da coleção The Interpreter's Bible. Ali, ele apresenta as diferentes facetas desse contexto histórico-social, sempre tendo em vista o "andar de 
cima": a organização política e econômica das diferentes regiões, a moral, a filosofia e a religião. Com exceção da escravidão, pouco demonstra sobre aspectos que atingem o povo comum das classes mais baixas e não fala de aspectos relacionados à vida cotidiana dessa gente. Isso ocorre por uma tendência geral na história de se trabalhar na perspectiva de quem tem o poder, organiza a sociedade e estabelece as leis.

A abordagem mais popular da realidade daquela época faz diferença para entender o contexto mais concreto no qual se movimentou o protocristianismo. Em seu livro Narrativa e cultura popular no Cristianismo Primitivo, Paulo Nogueira (2018) segue essa nova tendência no estudo geral do protocristianismo, permitindo vislumbrar aspectos que eram negligenciados, de um modo geral. Ele mesmo assume que essa abordagem passa pelo "estranhamento", pois coloca no centro temas citados de forma passageira. Nogueira explica: "Proponho que o leitor e a leitora se permitam ver como esse grupo é diferente de qualquer forma de cristianismo que conheçam ou que pratiquem" (2018, p. 15s). Nesse caso, há uma busca pelas expressões que indiquem a relação da religião com aspectos mais práticos e cotidianos da vida, em vez de preocupações mais globais e sistemáticas em definições doutrinárias.

Nessa perspectiva, o estudo do protocristianismo deve focar elementos considerados até estranhos ao ambiente cristão, como ritos mágicos, crenças dissonantes, textos rocambolescos e até grotescos, elementos pelos quais ideias mais populares eram divulgadas. Ficavam fora do "radar" das autoridades reconhecidas pelos cristãos. No caso do período do século I EC, isso nem mesmo está claro, porque as práticas e experiências religiosas protocristãs estavam ainda muito imersas no judaísmo, destoando das outras correntes apenas, talvez, na crença de Jesus como o Cristo. Em suma, práticas populares de religiosidade que fogem do controle oficial ou, pelo menos, esperado pelas lideranças. Aqui entra um conceito bastante importante, que está associado a essa abordagem: o de cultura popular. Nogueira se baseia em dois estudos importantes sobre o tema: o primeiro é o trabalho de Jerry Toner (2009), "que propõe uma discussão sofisticada sobre o tema, fugindo de estereótipos como a equiparação da cultura popular exclusivamente com o carnaval (ou carnavalização), ou com o folclore" (NOGUEIRA, 2018, p. 54). No mesmo lugar, Nogueira explica que Toner também "resiste a uma definição dualista da cultura popular em contraposição e em isolamento à da elite". Nesse caso, o estudo de Toner nos ajuda a perceber uma relação de articulação, de acordo com os interesses de cada grupo, em interação com outros grupos, o que permite uma percepção mais complexa do jogo social no mundo romano. 
Outra pesquisa apontada por Nogueira é a de Robert Knapp (2011), "que tem por objetivo 'entrar na mente' das classes baixas, entendendo suas atitudes, seus medos e esperanças” (NOGUEIRA, 2018, p. 55). Knapp delimita recortes sociais dentro dos $99 \%$ da população romana que não eram da elite, por meio de comparação com diversas fontes materiais, inclusive o Novo Testamento.

A partir dessas duas perspectivas, na forma como Paulo Nogueira trabalhou metodologicamente, é fundamental olhar para outros documentos para além do Novo Testamento e de materiais bíblicos. Entram aí análises sobre fontes diversas como os "Papiros Mágicos Gregos", manuais de interpretação de sonhos, amuletos e imagens etc. A partir deles se pode perceber como os cristãos lidaram com a magia, os sonhos, as orações, em especial para responder aos problemas do cotidiano, como fome, violência e perigos que viviam. Vejamos a seguir alguns desses aspectos.

\section{As práticas mágicas no protocristianismo}

Dentre as práticas religiosas populares que se podem recuperar dentro do protocristianismo estão aquelas ligadas à magia. Isso foi possível graças aos "Papiros Mágicos Gregos" (no latim Papiry Graecae Magicae, abreviados como PGM). São materiais relativamente simples, em que eram colocadas fórmulas a serem recitadas para alcançar coisas bem concretas da vida. Oriundos do Egito, eram escritos em pequenos pedaços de papiro, com o fim de serem guardados junto ao corpo ou em lugares específicos, diferente de um rolo completo. Os PGM “documentam instruções para os mais diferentes tipos de práticas, desde feitiços amorosos, de cura, exorcísticos, para obtenção de sonhos etc." (NOGUEIRA, 2020, p. 31). Em geral ligados a crenças politeístas sincréticas, em diversos momentos fazem uma aproximação à divindade Adonai, judaico-cristã. Isso não implica que tenham sido usados por membros das comunidades protocristãs, mas avaliaremos posteriormente.

Hans Dieter Betz (1986) explica que até há poucos séculos esse material era apenas citado em livros mágicos, pois, como esse tipo de empreendimento era questionado pelas instituições oficiais e pelo movimento nascente em torno de Jesus (cf. At 18), houve um movimento na Antiguidade de perseguição a essa prática que parte das autoridades e lideranças. Mas no conjunto do povo eram cultivadas e mantidas, de formas subversivas, a ponto de terem submergido na história. No século XIX, vieram à luz coleções particulares desses materiais que, posteriormente, foram vendidas a museus, onde então se iniciam as investigações recentes do material. Muitos materiais parecem ter se perdido definitivamente, mas uma quantidade bastante expressiva foi preservada, datada dos séculos II a IV EC. 
Nogueira (2020) considera que esse material deve ser entendido a partir de alguns pressupostos:

a) a magia como sistema semiótico que determina como o grupo concebe o mundo e organiza sua ação nele, a partir de suas necessidades concretas;

b) considerando que as práticas mágicas eram realizadas pelos grupos subalternos da sociedade romana, é necessário estudar a magia considerando os múltiplos testemunhos dela, de forma comparativa, inclusive;

c) não cabe, nessa perspectiva, diferenciar magia e religião, como se fazia na classificação acadêmica mais clássica. O estudo realizado a partir do olhar de baixo exige isso, porque eles não diferenciavam.

Nogueira resume assim seus indicativos:

com isso queremos dizer que magia é um produto religioso semiótica e semanticamente sincrético que, por sua vez, deve ser estudado nas variantes de materiais, semânticas, pragmáticas, que inclusive aglutinam textos de diferentes gêneros. (NOGUEIRA, 2020, p. 30).

Um tipo de feitiço muito comum encontrado entre os papiros é o de magia erótica, bastante presente encontrado na literatura de bruxas e nos PGM, conforme indica Daniel Ogden (2002). Eles podiam ser focados no desejo que o amor se realize, ou, numa direção oposta, maldições contra um concorrente ou contra alguém que não aceita o amor, bem frequente entre os fetícios. Havia imprecações para separar casais, para deixar um oponente sem desejo sexual, enquanto outras imprecações tinham a função de atrair alguém que não tinha interesse na pessoa que realizava o feitiço.

Ogden apresenta um caso curioso de uma narrativa feita por Jerônimo. Nela, um rapaz deseja uma virgem crente, e depois de não conseguir seduzi-la de forma alguma, vai ao Egito aprender feitiços de paixão com o sacerdote de Asclépio, de quem Jerônimo afirma que "não cura as almas, mas as destrói” (OGDEN, 2002, p. 230). O feitiço faz efeito e a moça fica enlouquecida, gritando pelo nome do rapaz; por isso, é levada a um mosteiro, onde ficava um ancião experiente em exorcismo e trava um diálogo com o demônio que está na jovem, que se afirma vítima do rapaz. Esse modo cortês do demônio é que chama a atenção na narrativa. Como se ele desejasse ser ajudado pelo exorcista.

Porém, esse texto tem elementos que mostram o quanto a magia era ruim e os cristãos lutavam contra ela. Para as pesquisas mais recentes, mais importante é perceber os casos em que a magia está a serviço dos cristãos, ou ainda, é utilizada por eles. É o que alguns amuletos indicam, conforme a análise que Paulo Nogueira (2020) fez de seis fontes. Vamos citar uma delas aqui, a título de exemplo. Nogueira traduz o texto de um amuleto feito em papiro, contendo invocação de entidades: 


\section{Amuleto para proteção de Silvano e para que ele tenha boa saúde}

Referência: P. Berlin 954: feito de papiro, datado do VI século.

Oh Senhor, Todo-Poderoso, e pai de nosso Senhor e Salvador Jesus Cristo, e tu Santo Sereno, Eu, Silvano, filho de Serapião, rogo e curvo minha cabeça diante de vós, pedindo insistentemente, que expulses de mim, vosso servo, o demônio do enfeitiçamento (probaskanías), da maldade, da inimizade, e afasta de mim toda a enfermidade e toda a debilidade, para que eu fique saudável e [mantendo-me saudável] recite a oração evangélica: Pai nosso, que estais nos céus, santificado seja teu nome, venha o teu reino, seja feita a [tua] vontade, na terra [como] no céu. O pão n[osso] de cada dia dai-[nos] hoje, e perdoa as nossas ofensas, conforme nós perdoamos os que nos ofenderam, e não nos conduzas em tentação, Senhor, livra-nos do ma[1. Pois tua é a glória pelos séculos ........ E os... no princípio era a palavr]a. Livro da geração de Jesus Cristo, filho [de Davi, filho de Abraão]. Oh luz de luz, Deus verdadeiro, concede-me, teu servo, a luz. Santo Sereno suplica por mim para fique completamente curado. (NOGUEIRA, 2020, p. 32).

Nogueira comenta que, o que caracteriza esse amuleto como cristão é a invocação inicial [Oh Senhor, Todo-Poderoso, e pai de nosso Senhor e Salvador Jesus Cristo] e o fato de ele não invocar nenhuma outra deidade. Um PGM padrão, não cristão, era bastante sincrético, podendo conter o nome do Deus judaico-cristão junto com outras divindades gregas, egípcias etc. Nogueira também comenta que, "diferentemente dos feitiços dos PGM, não encontramos referências a elementos materiais, como ervas, plantas, penas, etc. Caso houvesse a prescrição desses elementos, eles deveriam ter sido usados na confecção do amuleto" (2020, p. 33). Desse modo, Nogueira distingue entre os feitiços e amuletos, porque estes não precisam de preparo, apenas de confirmação mediante orações, gestos ou manter o amuleto preso junto ao corpo.

Também é comum nos PGM formas alfabéticas indicando nomes de entidades ou apenas como forma de invocação das forças que se pretendem alcançar. O PGM I.1-42 traz um feitiço de conjuração de um daimon (um espírito ou demônio), no qual se deve escrever certas letras, formando um desenho simétrico, como apresentado abaixo (Cf. BETZ, 1986, p. 61): ${ }^{3}$

A

E $\quad$ E

$\begin{array}{llllll}\bar{E} & \vec{E} & \bar{E}\end{array}$

$\begin{array}{llll}I & I & I\end{array}$

O O O 0 o
$0000000 \overline{0}$

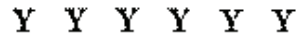

00000

$\begin{array}{llll}1 & I & I & I\end{array}$

$\overline{\mathbf{E}} \quad \overline{\mathbf{E}} \quad \overline{\mathbf{E}}$

E E

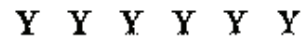 $\overline{\mathrm{O}} \overline{\mathrm{O}} \overline{\mathrm{O}} \overline{\mathrm{O}} \overline{\mathrm{O}} \overline{\mathrm{O}} \overline{\mathrm{O}}$}

A

Nomenclatura de referência de localização, ou seja, o Papiro número 1, linhas 1 a 42.

3 Ilustração retirada diretamente da obra. 
Essa forma é bastante utilizada em palavras das quais se pode retirar algum poder ou produzir um efeito mágico, auxiliando o encantamento. Também pode ser associado a divindades, como ocorre ao nome ABRAXAS, associado aos gnósticos, que vem do deus Mitra (cf. CIRLOT, 2001). Nos PGM, até mesmo o nome de Deus [Adonai] é organizado dessa forma, mais uma vez associando esses materiais a crenças judaicas ou cristãs.

Também é bastante frequente o uso de desenhos, seja com o objetivo de ilustrar a magia, seja como forma de indicar gestos que devem ser repetidos. Vários PGM mostram esses desenhos. Nogueira (2020), por exemplo, avaliou um deles, que aparece no amuleto "de exorcismo para proteção de uma mulher grávida". Nogueira comenta sobre o amuleto:

Trata-se de um amuleto com um longo texto, escrito em língua copta, acompanhado com imagens e palavras mágicas (voces magicae) diagramadas em formas geométricas. Não há citações e referências bíblicas (...). Não faltam, no entanto, indicações das funções do amuleto na vida de Sura, filha de Pelca, a destinatária (NOGUEIRA, 2020, p. 37).

No amuleto, além de uma grande elaboração textual, há um desenho que Nogueira classifica como "enigmático". A imagem indicada por ele será inserida abaixo (2020, p. 41):

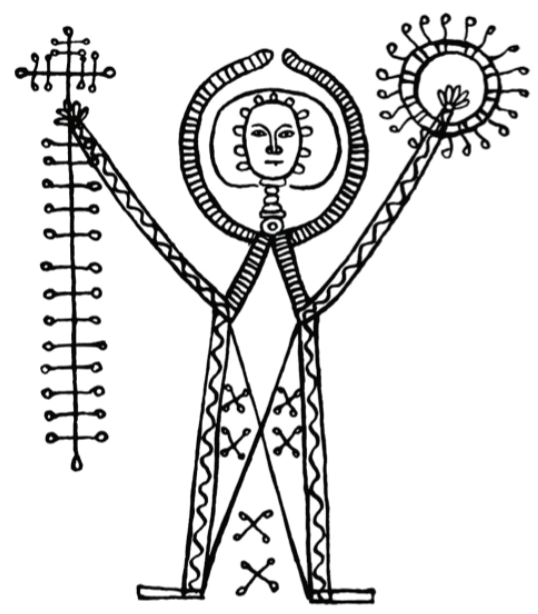

Após indicar algumas hipóteses de interpretação da imagem, como referência a Ap 1.16-18; como uma imagem andrógina ou angelical expressando poder e autoridade; como uma associação a divindades femininas, com a de Ártemis de Perge, Nogueira conclui que não é possível estabelecer uma relação concreta com nenhum desses elementos, pois é possível que esteja nele outros elementos simbólicos que não conhecemos (2020, p. 41s). Essa é uma característica das expressões religiosas vinculadas à cultura popular: 
ganham novas formas, realizam uma bricolagem cultural difícil de identificar a origem e significado. Mas, no fim, acabam por cumprir seu papel previsto, o de fazer rogos às divindades, ou simplesmente manipular as forças espirituais pelo uso da magia.

\section{Experiências sensórias como parte da experiência religiosa pro- tocristã}

Outro aspecto que caracteriza a dimensão popular do protocristianismo está relacionado às experiências extáticas que os crentes experimentavam nos cultos e momentos devocionais. Esse aspecto é mais perceptível a partir das comunidades paulinas do Mediterrâneo, porém deviam ser semelhantes nas comunidades palestinenses, ligadas aos apóstolos. Na perspectiva tradicional, tais elementos são considerados secundários ou até raros e não como parte da experiência cotidiana das comunidades protocristãs, como vemos, por exemplo, em Bultmann (2004, p. 409). Ele afirma que o estar no Espírito não deve ser entendido como um estado de êxtase. Ele pensa apenas na dimensão escatológica dessa presença, tirando o caráter vivencial da experiência pneumática.

Em uma perspectiva diferente, Klaus Berger (2011) analisou tais fenômenos a partir da psicologia histórica, que supera a perspectiva moderna: em seu recorte, ele entende ser necessário justamente "despir" os textos de significados atuais, em relação à experiência humana com o divino e entendê-las em seu próprio ambiente vital. É a busca pela compreensão das experiências religiosas descritas no Novo Testamento a partir do conceito de alteridade, tão caro à Antropologia. Por isso, ele classifica essas experiências em diferentes níveis. O trabalho de Berger é admirável e nos permite interpretar diversos aspectos que serão apontados aqui, mesmo que ele não tente reproduzir como essas experiências se davam na vida cotidiana. Ainda assim, considerando esse campo de pesquisa como um todo, fica evidenciado que tais experiências eram mais frequentes e valorizadas nas camadas populares do que entre as elites e grupos dominantes.

Esse fenômeno, em especial no recorte das visões de ascensão, é estudado por diversos pesquisadores e pesquisadoras, fora e dentro do Brasil. ${ }^{4}$ Os relatos bíblicos dão diversas notícias de que as reuniões dos protocristãos

\footnotetext{
Além do próprio Klaus Berger, podemos indicar os trabalhos de Colin Kruse (1994) e Ralph P. Martin (1986) sobre 2Coríntios, em que defendem que Paulo teve muitas experiências semelhantes à descrita no capítulo 12. Por sua vez, April D. DeConick (2001) considera o ambiente da experiência mística nos escritos de João e Tomé. No Brasil, as pesquisas de Jonas Machado (2009) e Sebastiana M. S. Nogueira (2016) analisam tais experiências em Paulo, tomando como ponto de partida os relatos de ascensão ao céu, de acordo com a tradição da Merkavá.
} 
eram marcadas por diferentes tipos de experiências extáticas, a partir das quais tanto podiam ocorrer o fenômeno da glossolalia quanto das percepções extracorporais, de onde se originam os relatos de viagens celestiais.

Cumpre comentar aqui que essas experiências não eram, nem exclusivas, nem originadas no ambiente do protocristianismo. Outros grupos contemporâneos, como os oráculos ou as pessoas envolvidas na religião de Ísis e outros cultos de mistério, tinham também fortes experiências extáticas. John E. Stambaugh e David L. Balch comentam a popularidade desses cultos mistéricos, que tinham forte relação com a "devoção popular a várias divindades do Oriente Próximo” (1996, p. 123):

Eles estimulavam duas tendências religiosas gerais do período cristão primitivo e também satisfaziam as necessidades geradas por essas tendências. Uma voltava-se para o sincretismo, o processo pelo qual os deuses semelhantes de diversos povos eram identificados e considerados como essencialmente o mesmo ser divino. Outra tendência voltava-se para o envolvimento emocional mais íntimo com o divino, e esses cultos orientais forneciam uma exótica vazão para essas necessidades religiosas. (STAMBAUGH; BALCH, 1996, p. 123).

Aqui nos interessa mais o aspecto do "envolvimento emocional" indicado pelos autores, ainda que o sincretismo seja parte desse envolvimento, considerando que vivências experimentadas em outras religiões podiam ser transportadas para o ambiente protocristão, mesmo que se fizesse necessariamente uma diferenciação entre elas, com o fim de minimamente ressignificar as experiências anteriores. Esse processo afetivo-experiencial é complexo e é regido, no caso das experiências extáticas, pelo princípio da percepção, ou seja, como as pessoas vivenciam os fatos e a realidade de forma subjetiva, conforme a perspectiva adotada por Klaus Berger (2011). Ele afirma:

Aquilo que nós designaríamos de "fatos" é experienciado diferentemente pelas pessoas no ambiente do Novo Testamento, especialmente quando se trata de "obras de Deus" ou de seu enviado escatológico e de quando se verbalizam experiências religiosas de tempo ali onde "tempo" está igualmente numa estreita relação com Deus. (BERGER, 2011, p. 133).

Berger entende que, por isso, para entender adequadamente as experiências relacionadas aos fatos e ao tempo, é necessário vinculá-las à experiência de Deus, que é o foco da situação vivenciada pelas pessoas. Neste sentido, Paulo Nogueira aponta a dificuldade de tal análise, ao afirmar que "não temos relatos muito explícitos sobre como os primeiros cristãos experienciavam a oração, o louvor, os sentimentos religiosos" (NOGUEIRA, 2003, p. 8s). 
Ainda assim, a partir do método comparativo com fenômenos similares, tanto do judaísmo quanto das religiões mistéricas, é possível, conforme assinalado acima, ter uma ideia desse quadro. Os materiais que foram indicados anteriormente apontam apenas um dos vários aspectos relacionados à experiência religiosa das comunidades protocristãs. Não há ali descrição de experiências extáticas, por isso nossa caminhada parte dessa comparação geral.

Os relatos visionários podiam ter caráter de experiências angelomórficas ou de viagens celestiais, às vezes reunindo as duas experiências. Isso tem sua origem na vivência mística judaica das experiências de Merkavá, termo cunhado a partir do relato da carruagem da glória de Deus em Ezequiel, mas utilizando a narrativa de Elias, em 2Reis 2, como horizonte, bem como nos textos denominados Hekhalot, onde o foco está na visão dos palácios celestiais, como em 1 Enoque. Esse é um aspecto importante do judaísmo rabínico antigo, de acordo com as pesquisas de Gershom Scholem (1995). Rachel Elior (cf. DeCONICK, 2006, p. 85) comenta que ambas as tradições são distintas em tempo e estilo, e indicam contextos socioculturais diferentes, porém compartilham aspectos comuns: excepcional interesse em santuários celestiais e anjos que indicam um padrão celestial de tempo sagrado, lugar sagrado e ritual sagrado; mostram como os visionários são chamados a esse santuário para terem a revelação do lugar santo; por fim, tem um interesse especial em descrever os céus e os anjos guardiões.

Toda essa longa digressão a respeito da mística judaica é importante para indicar um dos contextos no qual se deram as experiências extáticas do protocristianismo. Esse fenômeno místico e visionário mais ligado ao judaísmo foi assimilado e reelaborado pelas comunidades protocristãs. Por exemplo, nas experiências místicas de Paulo é possível traçar um paralelo com a tradição da Merkavá. Sebastiana Nogueira (2016), a partir da pesquisa de Alan Segal, descreve três aspectos que indicam essa aproximação:

1) a angelofania, a visão de um mediador angélico principal que, na mesma forma que o anjo do Senhor em Êxodo, carregava o nome de Deus ou, de alguma forma, participava da divindade de Deus - para o autor, é a figura que Paulo viu e com a qual se identificou, o Cristo crucificado; 2) a transformação - na tradição mística judaica, adeptos, heróis ou patriarcas podem ser transformados em figura de mediadores; 3) a ascensão - alguém pode ir ao céu não apenas no fim de sua vida, mas ainda enquanto em vida. (SEBASTIANA, 2016, p. 117).

Isso não deve nos confundir, justamente em função do fato dos protocristãos não terem desde cedo se autoidentificado como um novo grupo religioso, porém como um movimento, ou um grupo específico dentro das 
expressões do judaísmo plural do século I EC. ${ }^{5}$ Porém, antes de acharmos que tais fenômenos no protocristianismo são apenas revisões da literatura judaica, Machado indica como essas narrativas devem ser compreendidas:

Tais visões não são meros artifícios literários, mas testemunhos de experiência cultual. Não se trata apenas de releitura de tradições, mas de experiências litúrgicas místicas que formam a base para a recepção e modificações das imagens dos textos fundantes como Is 6, Ez 1, Dn 7 e 12. (MACHADO, 2009, p. 96s).

Entramos aqui no ponto que mais nos interessa: indicar as diversas experiências extáticas presentes no ambiente cúltico do protocristianismo. Além das experiências visionárias, que Paulo (2Co 12), João (de Patmos, no Apocalipse) e Pedro (em At 10) tiveram e foram expressamente descritas, podemos presumir que outras pessoas também tinham visões. Além disso, havia profecias e profetizas reconhecidas pela igreja (cf. At 21.9), que também estão imersos nesse ambiente, a tal ponto que At 13 fala em "profetas e mestres" na organização da Igreja da Antioquia, o que faz pensar se o carisma profético era reconhecido junto com o carisma de ensino como uma forma de liderança. ${ }^{6}$

Outro fenômeno importante que estava presente nesse mesmo contexto vital é o da glossolalia. Indicado em textos como Atos 2 e 1Coríntios 12 e 14, é um fenômeno de certo modo no mundo religioso helênico do período romano, tendo em vista os já citados cultos de mistério, os círculos de oráculos e outros ambientes similares. Ainda que tenham diferentes explicações e condições em que se deem, há um rico e amplo fenômeno de êxtase que provoca a glossolalia. Paulo Nogueira entende que esse fenômeno, no protocristianismo, deve ser vinculado ao misticismo judaico: "Mesmo sendo a glossolalia um fenômeno atestado em cultos helenísticos, inclusive na profecia mântica, seu contexto mais próximo no cristianismo primitivo é o misticismo apocalíptico. É nesse âmbito religioso que o elemento extático se desenvolve no judaísmo do período" (NOGUEIRA, 2003, p. 66), o que aproxima a glossolalia das experiências visionárias.

Há pouca evidência literária desse fenômeno, o que é natural, pois, como Nogueira lembra, "a forma típica de sua prática acontecia durante a espontaneidade do momento do culto" (2003, p. 67). Algo similar ao que

Sobre isso, ver minha pesquisa em Os Evangelhos Sinóticos. Origem, memória e identidade. São Paulo: Fonte Editorial, 2016, especialmente o capítulo 2, em que defino as comunidades protocristãs como grupo intrajudaico.

6 Guy Bonneau afirma que não é possível afirmar isso, pois esses textos "refletem o estado carismático do cristianismo, que, nos seus primórdios [o que denomino aqui de protocristianismo], bem distante de uma estrutura institucional, conhecia muito bem uma liberdade nas suas atividades e um entusiasmo no seu funcionamento" (BONNEAU, 2003, p. 77). 
ocorre em ambientes de culto pentecostal no Brasil e em outros lugares. São espaços de expressão espontânea e não controlada formalmente, onde as experiências pneumáticas são valorizadas e vivenciadas livremente. Mesmo no ambiente paulino, a tentativa de controle mais indica a falta dele do que o contrário (cf. 1Coríntios 14.1-19).

Essa realidade certamente era onde o povo simples mais se identificava com o ambiente da pregação cristã. É um equívoco pensar o mundo das comunidades protocristãs como altamente conceitual e fortemente organizado e doutrinariamente definido. Era o mundo das experiências, da sensibilidade, da busca da experiência de Deus no mundo vivencial, não como conceito formal ou filosófico.

Poderíamos ainda pensar um desdobramento dessa perspectiva de experiência religiosa popular, que é o exorcismo. Afinal, no imaginário judaico apocalíptico, o mundo espiritual não é composto somente por os anjos e a presença divina, mas também sua contraparte maligna, os demônios, que agem nas pessoas e lutam contra Deus. Um sinal bastante claro da centralidade desse tema é o fato de Jesus ter estado sempre em combate com demônios, sempre de forma vitoriosa. Berger comenta que "o Novo Testamento pressupõe uma maciça 'fé em demônios' (contar com demônios) que é tão desenvolvida como dificilmente em outras partes de seu meio ambiente. Qualquer tentativa de embelezar isso é inverídica e apologética" (BERGER, 2011, p. 79).

De acordo com Kenner Terra (2017), a origem dessa crença e sua centralidade nas comunidades protocristãs também está no mundo judaico. A partir dos textos judaicos pseudepígrafos como 1Enoque (o mito dos Vigilantes) e o Livro dos Jubileus, Kenner identifica a recepção dessa crença em Qumran e posteriormente no protocristianismo. Sobre isso ele comenta:

Os maus espíritos introduzidos na tradição dos Vigilantes, com seus novos traços, especialmente em 1Enoque 15 e Jubileus 10, podem ter influenciado ou servido material simbólico para o desenvolvimento da demonologia encontrada em alguns documentos de Qumran. Isso, desde a ideia dualista, onde se encaixam os seres malignos, até as próprias imagens do demoníaco em si, como seres que possuem corpos impuros. (TERRA, in CARNEIRO; SILVIO, 2017, p. 295).

Em relação à possessão demoníaca em si, Berger (2011) vai indicar diversos aspectos importantes para entender esse fenômeno: é uma experiência do alheio, do repugnante; uma experiência de impotência, onde demônios são personificados; estão num âmbito pré-moral; participam de um jogo de poder, no caso com Deus e Jesus. Por isso, Berger vai indicar as seguintes 
"funções corretivas do demonismo neotestamentário" (2011, p. 99), que listamos aqui de forma sucinta:

- Desvela traços malignos da imagem de Deus;

- Como são textos místicos, os exorcismos indicam a superação da impotência;

- O destrutivo se manifesta de modo integral, físico e espiritualmente.

- É uma força externa sobre o ser humano, para a qual a salvação não é questão de mudança, mas de libertação.

- É uma experiência de poder no âmbito da religião, que também se traduz como metáfora política. ${ }^{7}$

Por fim, Berger completa com a reflexão de que, neste aspecto, "o cristianismo não oferece uma mensagem, mas um mediador. Sua autoridade funciona como centro ordenador" (2011, p. 100).

\section{Considerações finais: a repercussão dessa temática para a pes- quisa do Novo Testamento}

Pensar o mundo religioso do protocristianismo, não como doutrina organizada, mas como experiência religiosa vivenciada pelas camadas inferiores da sociedade judaico-romana nos confronta com modelos de uma igreja desde sempre bem organizada e estável, ainda que denominada como "Igreja Primitiva". Pelo contrário, nos faz pensar o quanto os textos neotestamentários e extracanônicos são tentativas, da parte de diferentes grupos, de organizar esses fenômenos e ordenar a experiência com Deus. Por isso, a pesquisa do NT precisa levar em conta esses fenômenos, sob bases menos racionais e positivistas e mais pela abordagem do estudo das experiências religiosas, levando em conta seus aspectos psicossociais, antropológicos e existenciais.

Levantam-se, a partir dessa abordagem, algumas questões a serem investigadas: se as experiências religiosas eram fluídas e as fronteiras entre elas não estava claras, seria este o motivo concreto para certas orientações dos apóstolos com respeito às práticas nos cultos (Paulo aos Coríntios e aos Colossenses, João à sua comunidade etc.)? 'Teríamos aí uma primeira tentativa de ordenamento e padronização da parte das lideranças?

Outro ponto que se pode levantar é como essas experiências continuaram repercutindo nos séculos seguintes, já que os textos da Patrística pouco

\footnotetext{
Sobre isso, ver a abordagem demonstrei sobre o caso do Geraseno em Mc 5, no artigo "Jesus dominando sobre o mar: esperança em meio à tragédia no Evangelho de Marcos”, in: Estudos Bíblicos, 2015, p. 77-86.
} 
ou nada falam a respeito. Será que as camadas populares aderiram a um tipo de religiosidade mais formal no âmbito do culto e teriam direcionado sua mística popular para as formas de magia que encontramos nos PGM?

Isso nos ajuda a pensar o quanto os textos refletem preocupações de lideranças que tentam, a todo custo, definir as fronteiras entre o grupo interno das comunidades e outros grupos. Parece-nos que esse objetivo não foi plenamente alcançado, tendo em vista a necessidade sempre permanente dos líderes estabelecerem marcos identitários, como se pode perceber nos Pais da Igreja, tema para outro artigo. Isso demonstra que, como sempre ocorre, há uma distância entre o que a liderança formalmente expressa em termos de ideias de conduta e crenças e o que efetivamente o povo vive em sua realidade.

No fim das contas, por tudo que a história do Cristianismo tem demonstrado, sempre houve e sempre haverá, pelo menos, duas grandes expressões da fé cristã: a oficial, doutrinária, formal e institucionalizada, e a popular, focada na experiência, na espontaneidade e no dinamismo de movimento. O estudo do NT não pode mais subestimar a importância desses e outros temas, estudados a partir de baixo.

\section{Referências bibliográficas}

BERGER, Klaus. Psicologia histórica do Novo Testamento. Trad. Monika Ottermann. São Paulo: Paulus, 2011.

BETZ, Hans Dieter (ed.). The Greek Magical Papyri in translation. Including the Demotic Spells. Chicago: University of Chicago Press, 1986.

BONNEAU, Guy. Profetismo e instituição no Cristianismo Primitivo. Trad. Bertilo Brod. São Paulo: Paulinas, 2003.

BULTMANN, Rudolf. Teologia do Novo Testamento. Trad. Ilson Kayser. Revisão de Nélio Schneider. São Paulo: Teológica, 2004.

CARNEIRO, Marcelo. Os Evangelhos Sinóticos. Origem, memória e identidade. São Paulo: Fonte Editorial, 2016.

CARNEIRO, Marcelo. Jesus dominando sobre o mar: esperança em meio à tragédia no Evangelho de Marcos. Estudos Bíblicos, Petrópolis, v. 25, n. 125, p. 77-86, 2015.

CARNEIRO, Marcelo; GOMES, Silvio (org.). Manual de angeologia. São Paulo: Fonte Editorial, 2017.

CIRLOT, J. E. Dictionary of symbols. 2. ed. London: Routledge, 2001.

DeCONICK, April D. Voices of the mystics. Early Christian Discourse in the Gospel of John and Thomas and Other Ancient Christian Literature. Sheffield: Sheffield Academic Press, 2001.

DeCONICK, April D. (ed.). Paradise now. Essays on Early Jewish an Christian Mysticism. Atlanta: Society of Biblical Literature Press, 2006. 
KNAPP, Robert. Invisible romans. Cambridge: Harvard University Press, 2011.

KRUSE, Colin. II Coríntios: introdução e comentário. Trad. Oswaldo Ramos. São Paulo: Vida Nova, 1994.

MARTIN, Ralph P. 2 Corinthians. Nashville: Thomas Nelson Publisher, 1986.

NOGUEIRA, Paulo Augusto de Souza. Práticas mágicas no cristianismo primitivo: estudo da religião popular nos amuletos cristãos. Caminhando, São Bernardo do Campo, v. 25, n. 1, p. 27-45, jan./abr. 2020.

NOGUEIRA, Paulo Augusto de Souza. Experiência religiosa e crítica social no Cristianismo Primitivo. São Paulo: Paulinas, 2003.

NOGUEIRA, Paulo Augusto de Souza. Narrativa e cultura popular no Cristianismo Primitivo. São Paulo: Paulus, 2018.

SCHOLEM, Gershom. As grandes correntes da mistica judaica. São Paulo: Perspectiva, 1995.

STAMBAUGH, John E.; BALCH, David L. O Novo Testamento em seu ambiente social. Trad. João Rezende Costa. São Paulo: Paulus, 1996.

TONER, Jerry. Popular culture in ancient Rome. Cambridge: Polity Press, 2009. 